\title{
A PRODUÇÃO CAMPONESA DE FARINHA DE MANDIOCA NA AMAZÔNIA SUL OCIDENTAL
}

\author{
THE PEASANT PRODUCTION OF CASSAVA FLOUR \\ IN AMAZON SOUTH WEST
}

\section{LA PRODUCCIÓN DE HARINA DE YUCA EN LA AMAZONAS SUROESTE}

\author{
César Gomes de Freitas - Instituto de Educação, Ciência e Tecnologia do Vale do Juruá - \\ Cruzeiro do Sul - Acre - Brasil \\ cgfreitas@cesd.br
}

Cleilton Sampaio de Farias - Instituto de Educação, Ciência e Tecnologia do Vale do Juruá -

Cruzeiro do Sul - Acre - Brasil

cleilton.farias@ifac.edu.br

Olivier François Vilpoux - Universidade Católica Dom Bosco - Campo Grande - Mato Grosso do Sul - Brasil

vilpoux@ucdb.br

\section{Resumo}

Este estudo objetivou compreender as características da produção de farinha de mandioca no município de Cruzeiro do Sul, Acre, situado na Amazônia Sul Ocidental. Neste município, que não possui ligação rodoviária permanente com o restante do Brasil, as casas de farinha possuem forte participação no fornecimento de emprego e renda para a população local. A coleta e a análise dos dados foram realizadas no mês de outubro de 2009. Utilizou-se o método descritivo com amostragem de pequenos produtores do município mediante aplicação de questionário por meio de entrevistas pessoais (MALHOTRA, 2001). 0 questionário abordou temas qualitativos e quantitativos, por meio de perguntas estruturadas, dicotômicas, de múltipla escolha e escalonadas. Além das entrevistas com os produtores, foi realizada entrevista com a coordenação local da Secretaria de Estado de Extensão Agroflorestal e Produção Familiar. Enfim, nos resultados da pesquisa, encontramos evidências da predominância de referências camponesas entre os valores que orientam o cultivo da mandioca, a produção de farinha e a forma de organização social e territorial estabelecida na região.

Palavras-chave: camponês, mandioca, farinha, Cruzeiro do Sul, Amazônia Sul Ocidental.

\section{Abstract}

This study aimed to understand the characteristics of the production of cassava flour in the city of Cruzeiro do Sul, Acre, located in South West Amazonia. In this municipality, which has no permanent road link with the rest of Brazil, home flour are heavily involved in providing employment and income for local people. The data collection and analysis were conducted in October 2009. We used descriptive method with sampling of small producers in the municipality through a questionnaire via personal interviews (MALHOTRA, 2001).The questionnaire included qualitative and quantitative issues through structured questions, dichotomous, multiple choice and scaled. In addition to interviews with producers, was interviewing the local coordination of the Secretary of State Extension Agroforestry and Family Production. Finally, the results of the research found evidence of the predominance of peasant references between the values that guide the cultivation of cassava, the production of flour and form of social organization and territorial established in the region.

Key words: peasant, cassava flour, Cruzeiro do Sul, South Western Amazon. 


\section{Resumen}

Este estudio tuvo como objetivo conocer las características de la producción de harina de yuca en la ciudad de Cruzeiro do Sul - Acre, ubicado en el suroeste de la Amazonia. En este municipio, que no tiene ninguna vía de comunicación permanente con el resto de Brasil, la harina de casa están muy involucrados en la provisión de empleo e ingresos para la población local. La recolección de datos y análisis se llevaron a cabo en octubre de 2009. Se utilizó el método descriptivo con muestreo de los pequeños productores en el municipio a través de un cuestionario a través de entrevistas personales (MALHOTRA, 2001). El cuestionario incluyó temas cualitativos y cuantitativos a través de preguntas estructuradas, dicotómico, múltiples y escalada. Además de las entrevistas con los productores, se entrevistaba con la coordinación local de la Secretaría de Estado de Extensión Agroforestal y Producción Familiar. Finalmente, los resultados de la investigación encontró evidencias de la predominancia de las referencias de campesinos entre los valores que guían el cultivo de la yuca, la producción de harina y la forma de organización social y territorial establecido en la región.

Palabras clave: agricultor, harina de yuca, Cruzeiro do Sul, sur oeste de la Amazonía.

\section{Introdução}

A mandioca constitui um dos principais alimentos energéticos para cerca de 500 milhões de pessoas, sobretudo nos países em desenvolvimento, onde é cultivada em pequenas áreas com baixo uso de insumos e baixo nível tecnológico, por ser um produto rico em carboidratos. O Brasil é um dos grandes produtores de mandioca, representando mais de $15 \%$ da produção mundial. A produção brasileira nos últimos anos vem apresentando crescimento constante, totalizando, no ano de 2006, mais de 27 milhões de toneladas (IBGE, 2006). No Acre, o município de Cruzeiro do Sul é conhecido pela qualidade da farinha de mandioca que produz. Fabricada de forma totalmente artesanal, a farinha de mandioca constitui atualmente seu principal produto de exportação, sendo também relevante para o consumo interno. Em 2009, dos quase vinte e seis mil hectares plantados na Regional Administrativa do Juruá, praticamente metade era de mandioca. Os municípios com maior área plantada foram Cruzeiro do Sul (com 5.200 hectares) e Rodrigues Alves (4.200 hectares). ${ }^{1}$ Nestas localidades, a vida da comunidade gira em torno da fabricação da farinha. Isso tudo não significa, necessariamente, apenas uma estratégia econômica de obtenção de lucro, muito pelo contrário, uma parte da produção é destinada ao consumo da própria comunidade, que utiliza a farinha e os seus derivados em "quase" todas as suas refeições. Mais do que uma forma de obter lucro, a farinha está presente na vida dessas comunidades do município, que inclusive empresta seu nome para designar a melhor qualidade de farinha fabricada na região: a Farinha de Cruzeiro do Sul. 
Nesse contexto, este estudo objetivou compreender as características da produção de farinha de mandioca no município de Cruzeiro do Sul. Para tanto, realizou-se uma pesquisa descritiva com amostragem de pequenos produtores do município mediante aplicação de questionário por meio de entrevistas pessoais (MALHOTRA, 2001). O questionário abordou temas qualitativos e quantitativos, por meio de perguntas estruturadas, dicotômicas, de múltipla escolha e escalonadas. Além das entrevistas com os produtores, foi realizada entrevista com a coordenação local da Secretaria de Estado de Extensão Agroflorestal e Produção Familiar. Na pesquisa descritiva, o universo escolhido foi o dos pequenos produtores do município de Cruzeiro do Sul, Acre. Foram escolhidos aleatoriamente setenta produtores, os quais constituem a amostra estudada para a pesquisa. A coleta e a análise dos dados foram realizadas no mês de outubro de 2009.

Enfim, nos resultados da pesquisa encontramos evidências da predominância de referências camponesas entre os valores que orientam o cultivo da mandioca, a produção de farinha e a forma de organização social e territorial estabelecida na região.

\section{Os fundamentos da produção camponesa}

Para Marques (2008, p. 58), o campesinato é uma classe social (uma classe estranha) e não apenas um setor da economia, uma forma de organização da produção ou um modo de vida. Para a autora, a sustentação dessa afirmação encontra-se em Shanin:

Segundo Shanin (1979, p. 228), o campesinato é, ao mesmo tempo, uma classe social e um "mundo diferente", que apresenta padrões de relações sociais distintos - ou seja, o que também podemos denominar de modo de vida. Para ele, o campesinato é uma classe social de baixa "classicidade" que se insere na sociedade capitalista de forma subordinada e se levanta em momentos de crise. (MARQUES, 2008, p. 59)

Nesse sentido, faz-se necessária uma explicação do que é uma classe, o que ela faz e como ela se expressa. Para isso, a autora busca em Thompson (1987, p. 10) a resposta para essa questão.

A classe acontece quando alguns homens, como resultado de experiências comuns (herdadas ou partilhadas), sentem e articulam a 
identidade de seus interesses entre si, e contra outros homens cujos interesses diferem (e geralmente se opõem) dos seus. A experiência de classe é determinada, em grande medida, pelas relações de produção em que os homens nasceram - ou entraram involutariamente. A consciência de classe é a forma como essas experiências são tratadas em termos culturais: encarnadas em tradições, sistemas de valores, idéias e formas institucionais. (THOMPSON, 1987, p. 10)

Depreende-se que a classe não pode ser compreendida como uma categoria analítica que se aplica aos grupos sociais como decorrência direta de sua posição no interior das relações de produção, pois, no caso do campesinato, que se caracteriza por uma organização social específica que ora serve aos interesses capitalistas, ora lhes é contraditória, isso seria incompatível. A condição do campesinato pode ser agravada na análise do modo de vida do camponês, uma vez que esse apresenta simultaneamente uma relação de subordinação e de estranhamento em relação à sociedade capitalista. Portanto, o campesinato é uma classe estranha, mas é classe.

São várias as formas para designar o camponês e o seu opositor “o latifúndio”. Segundo Wright (2005, p. 114) o latifúndio é "um aspecto formal da propriedade fundiária, que quer dizer, rigorosamente, grande propriedade, como latifundiário quer dizer grande proprietário”. Assim, seja ela produtiva ou não, se for grande propriedade será classificada como latifúndio.

Já as designações da palavra camponês eram pejorativas e negativas. Em outras regiões, é designado por nomes como caipira (São Paulo, Minas Gerais e Goiás), caiçara (litoral paulista), colono ou caboclo (sul do país), dependendo de sua origem, imigrante ou não. O mesmo também acontecia com os grandes proprietários de terra, que eram conhecidos como estancieiros, senhores de engenho etc. Observe-se o conceito de camponês ou campesinato nas palavras de Marques (2008, p. 60):

O campesinato se refere a uma diversidade de formas sociais baseadas na relação de trabalho familiar e formas distintas de acesso à terra como o posseiro, o parceiro, o foreiro, o arrendatário, o pequeno proprietário etc. A centralidade do papel da família na organização da produção e na constituição de seu modo de vida, juntamente com o trabalho na terra, constituem os elementos comuns a todas essas formas sociais.

Por conta da imagem degradada e desgastada que é passada pela mídia e pelo poder hegemônico sobre o camponês, no final do século 
XX, ocorreu a proposição da evolução teórica do conceito de camponês para agricultor familiar. Esse movimento foi fortemente incentivado pelo Estado e abraçado por muitos intelectuais, sobretudo de direita. No entanto, isso não passa de uma tentativa de adaptar o campesinato ao novo momento na agricultura diante do avanço do capitalismo no campo. Essa tentativa de acabar com as proposições camponesas fracassa diante dos novos acontecimentos no campo, ou seja, no novo cenário, o Movimento dos Trabalhadores Rurais Sem Terra (MST) passa a se autodefinir como um movimento camponês, filiando-se à Via Campesina, organização internacional que congrega camponeses de várias partes do mundo, e contribuindo ativamente para as ações que esta realiza no Brasil.

Essa proposição defendida por autores como Abramovay (1992) e Lamarche (1993 e 1998) enfatiza que ser agricultor familiar é estar vinculado a uma profissão que possui fortes ligações com o mercado por ter características empresariais, dinamismo técnico e capacidade de inovação, ou seja, cria-se uma imagem desprovida de qualquer conflito ou contradição ao desenvolvimento capitalista. No entanto, o trabalho de Lamarche, em via de conclusão, reafirma que o agricultor familiar não difere do camponês, muito pelo contrário, possui várias características que lhe são similares.

O estabelecimento familiar moderno define-se como uma unidade de produção menos intensiva, financeiramente pouco comprometida e, principalmente, muito retraída em relação ao mercado; com efeito, a maior parte de suas produções é parcialmente reutilizada para as necessidades da unidade de produção ou autoconsumidas pela família; nunca é totalmente comercializada. [...] Podemos admitir, no que diz respeito às variáveis consideradas, que o estabelecimento familiar moderno funciona sensivelmente como estabelecimento de tipo camponês, com mais técnica e mais necessidades. (LAMARCHE, 1998, p. 314; grifos do autor)

Para melhor caracterizar o trabalho camponês, encontramos alguns elementos que formam a produção camponesa: força de trabalho familiar, parceria com outros camponeses, o trabalho acessório, trabalhadores temporários, socialização do camponês, propriedade da terra, propriedade dos meios de produção e, por fim, a flexibilidade da jornada de trabalho (OLIVEIRA, 2001).

Nas propriedades camponesas, suas características são distintas da propriedade capitalista, seu elemento principal de produção é a comida 
para a própria subsistência, e a venda do excedente no comércio local, como bem enfoca Almeida (2007, p. 10). Segundo Farias (2011, p. 7), é na propriedade camponesa que se encontra o sentido de viver do camponês, a sua fonte de vida, a sua identidade, as suas histórias, o seu imaginário enquanto ser, e é por tudo isso que a posse da terra foi e ainda é hoje a sua principal riqueza, espaço principal de sua expressão e reprodução da territorialidade. Portanto, é na iminência da separação do camponês "da sua" terra - com a destruição da sua territorialidade - que surgem os conflitos.

Considerando o conceito e as características da produção camponesa, apresentaremos a seguir as similaridades do trabalho camponês na produção de farinha no município de Cruzeiro do Sul na Amazônia Sul Ocidental. Partiremos das características do plantio e da colheita de mandioca, depois enfocaremos os trabalhadores da farinha: "farinheiros", a organização da produção e, por fim, a fabricação da farinha.

A cultura da mandioca para produção de farinha: as características do plantio e da colheita

Entre os principais fundamentos da economia camponesa, a propriedade da terra e dos meios de produção sempre mereceu destaque, por nisso residir o poder da liberdade do trabalhador. Para Oliveira (2007, p. 41), a propriedade da terra é um dos elementos estruturais da produção camponesa, é o local de trabalho e possui sentido amplo:

g) - a propriedade da terra - é, na unidade camponesa, propriedade familiar, privada para muitos, porém diversa da propriedade privada capitalista (a que serve para explorar o trabalho alheio); na propriedade familiar se está diante da propriedade direta de instrumentos de trabalho que pertencem ao próprio trabalhador, é terra de trabalho, é propriedade do trabalhador, não é, portanto, instrumento de exploração; nesse particular, três situações podem-se colocar para o camponês: ele ser camponês proprietário, ser camponês-rendeiro (pagar renda para poder ter acesso à terra), ou ser camponês-posseiro (recusar-se a pagar a renda e apossar-se da terra). (OLIVEIRA, 2007, p. 41)

O cultivo da mandioca em Cruzeiro do Sul se faz, sobretudo, em propriedade privada familiar. Em 2009, conforme dados de pesquisa empírica, $69,7 \%$ das casas de farinha ou farinheiras cultivaram a mandioca que processaram. Somente $30,1 \%$ dos produtores compram a 
mandioca utilizada na fabricação da farinha. Destes, 4,5\% compram até $25 \%$ do total utilizado, $7,5 \%$ compram de $25 \%$ a $50 \%$ da matéria-prima, $12,1 \%$ adquirem entre $51 \%$ e $75 \%$, 4,5\% adquirem entre $75 \%$ e $99 \%$, e 1,5\% adquire $100 \%$ da matéria-prima utilizada.

Nesse caso, mesmo a compra da mandioca é feita como estratégia de reprodução camponesa. Existe época em que não é possível o plantio desta cultura, então se recorre à ajuda mútua ou à parceria para garantir a renda. Um camponês fornece a casa de farinha e o outro contribui com a matéria-prima. Ambos trabalham no processamento e repartem o resultado do trabalho. A maior parte da retribuição para o fornecimento da mandioca é feita em dinheiro, ou seja, 77,2\% do total. Em alguns casos, essa retribuição é feita em espécie, ou seja, em farinha, totalizando nesse caso $22,7 \%$ do montante.

A questão da ajuda mútua e da parceria é fortalecida quando analisamos a distância entre a área em que a mandioca foi adquirida e a farinheira em que será processada, indicando uma proximidade ou vizinhança entre ambas. Em média, 55\% da matéria-prima provêm de até cinco quilômetros de sua farinheira, $30 \%$ provêm de regióes entre cinco e dez quilômetros de distância e 15\% precisam percorrer mais de quinze quilômetros para adquirir a mandioca.

O pessoal ocupado no plantio e na colheita da mandioca é, sobretudo, da própria família. Nesse caso, quanto maior a família, maior também a mão de obra. Para Oliveira (2007, p. 41; grifo do autor), "a força de trabalho familiar - é o motor do processo de trabalho na unidade camponesa; a família camponesa é um verdadeiro trabalhador coletivo”. Então, 15\% possuem famílias formadas por três pessoas trabalhando nos cultivos, $35 \%$ possuem famílias formadas por quatro pessoas, $15 \%$ com cinco, seis e sete pessoas, e $5 \%$ com famílias formadas por 10 pessoas.

No setor de fabricação, 46,7\% das casas pesquisadas possuem colaboradores para auxiliar nos trabalhos de produção da farinha. Destas, $14,2 \%$ possuem até três funcionários, $21,2 \%$ possuem entre quatro e seis funcionários, $8,5 \%$ possuem entre sete e nove funcionários e 2,8\% contam com mais de dez funcionários. O salário médio destes colaboradores é de R\$ 400,00 por mês.

Quando a unidade camponesa consegue a sua sustentabilidade através da produção de farinha, os seus componentes se ocupam exclusivamente disso. Nesse caso, retira-se a proporção da farinha para o consumo da família e comercializa-se o excedente para adquirir os outros 
produtos necessários para a sobrevivência de todos os seus membros. Quando a produção da farinha não permite isso, faz-se o uso do trabalho acessório (OLIVEIRA, 2007, p. 41) em que componentes da família procurarão, temporariamente, ocupação fora da unidade camponesa para complementar a renda. A maioria dos produtores entrevistados, 55,7\%, trabalha doze meses por ano na produção de farinha, ou seja, sobrevive exclusivamente da produção da farinha. Outros $25,7 \%$ trabalham de seis a onze meses por ano, tendo de complementar a renda e/ou a produção com outras coisas e somente $15,7 \%$ trabalham menos de seis meses por ano na produção da farinha.

Em relação à escolaridade dos produtores de farinha entrevistados, $15,7 \%$ são analfabetos, $55,7 \%$ possuem o primeiro grau incompleto, $10 \%$, o primeiro grau completo, $10 \%$ possuem o segundo grau incompleto e 7,1\% possuem o segundo grau completo. Esses dados refletem a situação de exclusão e de abandono do campo. Poucas pessoas têm acesso e oportunidade de estudar e de seguir estudando, fato que compromete o futuro e a melhoria das condições de produção e das pessoas que vivem dos frutos do campo.

Dos entrevistados, 38,5\% responderam positivamente quando questionados se já participaram de algum tipo de treinamento. A maioria, $64,2 \%$, destes frequentou cursos de técnicas sobre produção agrícola. Entre os demais treinamentos citados, a pesquisa apresenta: técnicas de produção industrial - 3,5\%, comercialização - 7,1\%, cooperativismo - 10,7\%, piscicultura $-10,7 \%$ e boas técnicas de produção $-3,5 \%$.

Percebemos, também, a presença de jornada de trabalho assalariada em apenas $10 \%$ das casas de farinha pesquisadas. Como a unidade camponesa se move por força da família, esses trabalhadores somente atuarão para complementar a força de trabalho, pois, segundo Oliveira (2007, p. 41) a jornada de trabalho assalariada:

[...] aparece na unidade de produção camponesa como complemento da força de trabalho familiar em momentos críticos do ciclo agrícola, nos quais as tarefas exigem rapidez e muitos braços; essa força de trabalho assalariada na unidade camponesa pode, em determinados momentos, começar a ser permanente, e o camponês passa, então, a combinar as duas forças de trabalho, a familiar e a assalariada.

Esses trabalhadores assalariados são diferentes dos camponeses, possuem formação escolar e noções de escritório, atuam principalmente 
na comercialização da produção e, por isso, recebem salário médio de R\$ 900,00 mensais.

\section{A fabricação da farinha}

Os meios de produção utilizados na fabricação da farinha, assim como a terra usada para o cultivo da mandioca, são de propriedade da família. As casas de farinha ou "farinheiras", designações para as fábricas onde se processa a mandioca, são locais simples, muitas vezes qualificadas como rústicas por apresentar, em sua maioria, aspectos ligados ao trabalho manual e artesanal. Elas são quase uma extensão da própria casa do camponês, pois se localiza proximamente a ela.

As características das casas de farinha são similares às moradias tradicionais da Amazônia: construção em madeira, chão de barro (em alguns casos em alvenaria), cobertura de palha (obtida de palmeiras da região), ausência de água canalizada e ausência de local apropriado para destinação de resíduos. Mas, a fábrica e tudo o que há nela - os meios de produção - é de propriedade da família camponesa, que não destina recursos para modernizá-la. Quanto a esse aspecto, Oliveira (2007, p. 41) esclarece:

[...] exceto a terra, na maioria dos casos os meios de produção são em parte adquiridos, portanto mercadorias, e em parte produzidos pelos próprios camponeses; como consumidor de mercadorias (instrumentos de trabalho, por exemplo), o camponês se vê subordinado ao capital, que lhe vende produtos caros e lhe paga preço baixo pelos produtos agrícolas.

Nesse sentido, dos produtores entrevistados para a presente pesquisa, sessenta e sete $(95,7 \%)$ trabalham em casas de farinha constituídas como empresas privadas, ou seja, da própria família, somente dois produtores $(2,8 \%)$ participam de empresas cooperativas e apenas um $(1,4 \%)$, de empresa comunitária.

Geralmente, não há máquinas para auxiliar na cadeia da farinha. O plantio é feito todo manualmente. Raras vezes ocorre a mecanização da terra para plantio e o transporte da mandioca para a fábrica se faz principalmente pela carreta de tração animal ou, como é conhecida na região, a “carroça de boi”. Nesse caso, são 87,1\% dos produtores, enquanto que $7,1 \%$ transportam o produto em sacos pelos próprios trabalhadores, e somente um produtor $(1,4 \%)$ o transporta por meio de caminhão. 
Em todas as casas de farinha visitadas, tanto o descarregamento quanto o descascamento é feito de maneira manual. O descascamento da mandioca é realizado por equipes formadas por até três pessoas em 18,9\% das casas de farinha; por equipes de quatro a sete pessoas, em 75,6\% delas e por equipe de oito a dez pessoas em $5,4 \%$ das casas visitadas.

Um dos únicos recursos "tecnológicos" usados na moagem da mandioca é o ralador que é movido a energia elétrica. A moagem é realizada pela grande maioria das casas, ou seja, $90 \%$ por meio de ralador de mandioca empurrado a mão. Essa forma de ralar é perigosa em vista da ausência de proteção para as mãos no momento de empurrar a mandioca em direção ao ralador, as consequências são alguns acidentes e amputações de dedos e mãos.

Quando termina a ralação da mandioca, antes de levar os resíduos ao forno, é necessário retirar o excedente de água da massa para torná-la mais seca. Verifica-se que $68,5 \%$ realizam essa atividade de prensagem por meio de prensa de madeira com alavanca, $14,2 \%$ usam prensa com rosca, $10 \%$ realizam o processo por meio de prensa hidráulica e 4,2\% utilizam o "tipiti", a prensa tradicional de fibra.

O líquido retirado da massa após a prensagem é conhecido por “manipueira” e, se despejado na vegetação, pode matá-la. Contudo, quando tratado, pode vir a ser usado pela culinária local de várias maneiras. Transformado em tucupi, pode compor pratos regionais como a conhecida “rabada no tucupi” ou o "tacacá”. No entanto, apenas $4,2 \%$ ou seja, três das setenta casas de farinha visitadas pela pesquisa recupera a água da prensa para produção de tucupi.

Dos produtores que não realizam o reaproveitamento da água, 87,6\% responderam que a água da prensa não recuperada é despejada diretamente nos arredores da casa de farinha, 7,5\% fazem uso de uma lagoa de decantação e 4,6\% realizam o despejo desta água em um rio.

Quando no forno para ser torrada, a massa necessita ser constantemente revolvida para que não queime. Esse processo também é feito, em sua maioria, ou seja, 97,1\% do totalizado, de forma manual. Apenas 2,9\% dos produtores fazem uso de peneira mecanizada no processo de revolvimento da farinha.

Quanto ao processo de secagem da farinha, 72,8\% das casas de farinha possuem dois fornos para sua realização, 18,5\% utilizam apenas 
um forno, 7,1\% possuem três fornos e 1,4\% possui mais de quatro fornos para a secagem.

Em relação ao formato dos fornos, 51,4\% deles são quadrados, 41,4\% possuem o formato retangular e 5,7\% são redondos. Ainda sobre os fornos, $94,2 \%$ deles possuem fundo plano e apenas $5,7 \%$ possuem fundo arredondado. Todos os produtores fazem o revolvimento manual da farinha nos fornos e somente $14,2 \%$ dos fornos dispõem de chaminé.

Um dado preocupante revelado na pesquisa é que, para 91,4\% dos entrevistados, a lenha utilizada nos fornos durante o processo de produção da farinha é adquirida nos arredores da empresa, 5,7\% adquirem madeira de fornecedores locais e 1,4\%, de fornecedores de outra região do estado. Estes dados mostram um forte impacto ambiental relacionado à atividade das casas de farinha. Todos os produtores pesquisados indicaram o uso de madeira nativa nos fornos durante o processo de produção da farinha.

Com relação ao tipo de farinha produzida, verifica-se grande diversificação neste quesito. O maior percentual, 72,8\% dos produtores pesquisados, indicou trabalhar com a produção dos tipos de farinha branca e farinha amarela. Entre estes, $25,7 \%$ dedicam $50 \%$ da produção a cada um destes tipos de farinha. A pesquisa ainda apresentou os tipos de farinha com coco com 11,3\%, farinha carimã com 11,1\% e 4,8\% dos produtores trabalham com a farinha mista. A mudança na cor da farinha é resultado da adição de corantes à massa durante a secagem. O açafrão é utilizado por $65,7 \%$ dos produtores enquanto que $4,2 \%$ utilizam o urucum ou o colorau.

\section{A organização e reprodução da produção}

As características da produção da farinha nos levam a crer que há muitos problemas a serem superados. Inserção de máquinas no plantio e colheita da mandioca, melhoramento das condições sanitárias das fábricas e adição de tecnologias em todas as fases do processamento: raspagem, ralação e secagem. Nada disso não é empecilho para minimizar esta economia, muito pelo contrário, ela permanece forte e se reproduzindo a cada ano. Com ela sobrevivem várias famílias e, além disso, gira em seu entorno uma economia regional. Nesse caso, para o melhoramento e expansão da produção camponesa da farinha são necessários alguns investimentos: 
Em geral, o processo de reprodução da produção camponesa é simples, o que significa dizer que o camponês repõe, a cada ciclo da atividade produtiva, os meios de produção e a força de trabalho para a repetição pura e simples dessa atividade produtiva. E esse processo de reposição pode se dar por meio da produção direta ou por meio da troca monetária. (OLIVEIRA, 2007, p. 42)

No caso da economia da farinha, poucos possuem a intenção de investir para melhorar ou expandir a produção. Entre os produtores que pretendem realizar investimentos, $28,5 \%$ farão investimento na melhoria da estrutura, 7,1\% investirão no aumento da produção e 2,8\% realizarão investimentos na melhora da qualidade do produto. Os 57,1\% restantes dos produtores não pretendem realizar investimentos, por não possuírem recursos financeiros para isso.

Quando questionados se realizaram algum investimento nos últimos três anos, 68,5\% dos produtores de farinha responderam negativamente. Dentre os que realizaram investimentos nos últimos três anos, 21,4\% investiram na melhora da estrutura da casa de farinha e 2,8\% investiram na construção e ou reforma do piso das casas de farinha.

Essas deficiências são superadas com a união e cooperação entre camponeses onde todos ajudam a todos. Considerando a carga de trabalho que realizam, os encontros nem sempre são possíveis, mesmo assim sempre ocorrem. Ao menos uma vez por ano, $24,2 \%$ dos produtores se encontram, contudo $10 \%$ dos produtores garantem que esse encontro ocorre uma vez por ano. Outros $7,1 \%$ de produtores se encontram de duas a quatro vezes por ano, enquanto que $14,2 \%$ responderam que o encontro ocorre todo mês e a maior parte $(45,7 \%)$ afirma que o encontro ocorre semanalmente.

Além disso, a associação também é uma oportunidade de fortalecer a produção, mas poucos participam, ou seja, somente $28,6 \%$ dos entrevistados, sendo que, desses, $17,1 \%$ participam apenas de vez em quando e $11,4 \%$ participam com maior assiduidade, estando presentes em todas as reuniões. Nenhum dos entrevistados faz parte da diretoria de alguma associação.

Alguns desses produtores já tiveram acesso a crédito bancário, mas não foram bem sucedidos, o que resultou em insatisfação com a instituição bancária, nesse caso o Banco do Brasil. Essa insatisfação é expressa na nota com que avaliaram a atuação do banco: a nota média atribuída numa escala de um a dez (sendo 01, ruim e 10, excelente) pelos 
produtores entrevistados em relação à atuação do Banco do Brasil foi 02 (dois).

Também existem problemas na atuação da assistência técnica e extensão rural oferecida pelo poder público, pois a nota média atribuída na mesma escala de um a dez (sendo 01, ruim e 10 excelente) pelos produtores entrevistados em relação à atuação da SEAPROF - Secretaria de Estado de Extensão Agroflorestal e Produção Familiar foi 03 (três).

\section{Considerações finais}

Enfim, encontramos evidências da predominância de referências camponesas entre os valores que orientam o cultivo da mandioca, na fabricação da farinha e na forma de organização social e territorial estabelecida na região. Portanto, as evidências de aplicação das referências camponesas nos valores que orientam o cultivo da mandioca, a fabricação da farinha e a forma de organização social e territorial da produção são os fundamentos que garantem a reprodução desta economia na região. Sem estes atributos, não seria possível a sua produção ou a venda pelo preço que é estabelecido. Enfim, esta produção é contraditoriamente apropriada pelo capitalismo no momento da circulação no mercado, quando há uma adição considerável no valor do produto com a extração da renda capitalista.

\section{Nota}

1. Referem-se a uma "sub-região" que corresponde ao estado do Acre, sul e sudoeste do Amazonas e o estado de Rondônia. Trata-se de uma área em que os processos de ocupação estiveram ligados à economia da borracha natural (SILVA, 2003, p. 52).

\section{Referências}

ABRAMOVAY, Ricardo. Os paradigmas do capitalismo agrário em questão. São Paulo/Rio de Janeiro/Campinas: Hucitec/ANPOCS/Ed. Unicamp, 1992.

ALMEIDA, Rosemeire A. O sentido da terra camponesa: práticas de distinção. In: III Simpósio Internacional de Geografia Agrária e IV Simpósio Nacional de Geografia Agrária "Jornada Orlando Valverde" - SINGA 2007. Londrina, PR, UEL, 2007. 
FARIAS, C. S. A ação do Estado e a manipulação do território. In: Anais do II Simpósio brasileiro de geografia política, território e poder - GEOSIMPÓSIO e I Simpósio Internacional de geografia política e territórios transfronteiriços GEOTRANS. Foz do Iguaçu: Faculdade Dinâmica das Cataratas - UDC, 2011. ISSN 0103-3560X.

IBGE, Instituto Brasileiro de Geografia e Estatística. Censo agropecuário, 2006. Disponível em: www.ibge.gov.br. Acesso em: 20 set. 2010.

LAMARCHE, Hugues (Coord.). A agricultura familiar: uma realidade multiforme. Campinas, Ed. Unicamp, 1993.

LAMARCHE, Hugues (Coord.). A agricultura familiar: do mito à realidade. Campinas, Ed. Unicamp, 1998.

MALHOTRA, N. K. Pesquisa de marketing: uma orientação aplicada. Trad. Montingelli, N. Jr. e Farias, A. A. de. 3. ed. Porto Alegre: Bookmann, 2001.

MARQUES, Marta Inez Medeiros. A atualidade do uso do conceito de camponês. Revista Nera. São Paulo, v. 11, n. 12, p. 57-67, 2008.

OLIVEIRA, Ariovaldo Umbelino de. A agricultura camponesa no Brasil. 4. ed. São Paulo: Contexto, 2001.

. Modo de produção capitalista, agricultura e reforma agrária. São Paulo: Lābur Edições, 2007.

SILVA, Sílvio Simione da. Na fronteira agropecuária acreana. Rio Branco: LEUPAG-DEGEO/UFAC, 2003.

THOMPSON, Eric P. A formação da classe operária inglesa: a árvore da liberdade. Rio de Janeiro: Paz e Terra, 1987.

WRIGHT, Paulo. Contribuição ao aprofundamento da análise das relações de produção na agricultura brasileira. In: STEDILE, João Pedro. (Org.). A questão agrária no Brasil: o debate na esquerda: 1960-1980. São Paulo: Expressão Popular, 2005.

César Gomes de Freitas - Mestre em Desenvolvimento Local pela Universidade Católica Dom Bosco. Professor do Instituto de Educação, Ciência e Tecnologia do Vale do Juruá.

Cleilton Sampaio de Farias - Mestre em Desenvolvimento Regional pela Universidade Federal do Acre. Professor do Instituto Federal de Educação, Ciência e Tecnologia do Acre.

Olivier François Vilpoux - Doutor em Engenharia de Produção pelo Institut National Polythecnique de Lorraine - Paris/França. Professor da Universidade Católica Dom Bosco. 